\title{
Safe drinking water in regional NSW, Australia
}

\section{Paul M Bylevelda,b, Sandy D Leaskª, Leslie A Jarvis ${ }^{a}$, Katrina J Walla, Wendy $\mathrm{N}$ Henderson ${ }^{\mathrm{a}}$ and Joshua E Tickella}

a Water Unit, Environmental Health Branch, Health Protection NSW, Sydney, Australia

b Corresponding author: paul.byleveld@doh.health.nsw.gov.au

\section{Article history}

Publication date: April 2016

Citation: Byleveld PM, Leask SD, Jarvis LA, Wall KJ, Henderson WN, Tickell JE. Safe drinking water in regional NSW, Australia. Public Health Res Pract. 2016;26(2):e2621615. doi: http://dx.doi. org/10.17061/phrp2621615

\section{Key points}

- The Australian drinking water guidelines framework offers a holistic, risk-based approach to managing drinking water quality

- The Public Health Act 2010 requires water suppliers to implement a quality assurance program to address the framework

- NSW Health has supported water utilities, private suppliers and water carters to meet this requirement

- There is an ongoing need for water suppliers to identify and control water quality risks

\section{Abstract}

The New South Wales (NSW) Public Health Act 2010 requires water suppliers to implement a drinking water quality assurance program that addresses the 'Framework for management of drinking water quality' in the Australian drinking water guidelines. NSW Health has recognised the importance of a staged implementation of this requirement and the need to support regional water utilities. To date, NSW Health has assisted 74 regional utilities to develop and implement their management systems. The Public Health Act 2010 has increased awareness of drinking water risk management, and offers a systematic process to identify and control risks. This has benefited large utilities, smaller suppliers, and remote and Aboriginal communities. Work is continuing to ensure implementation of the process by private suppliers and water carters.

\section{Introduction}

NSW Health is the public health regulator of drinking water in New South Wales (NSW), Australia. In regional NSW, drinking water is provided by 95 water utilities - mostly local councils - which serve around 1.7 million people through more than 300 water supplies. Drinking water is also provided to more than 60 discrete Aboriginal communities, many in remote areas. In addition, many facilities - such as bed and breakfast facilities, farmstays, caravan parks, school camps, national parks and tourist attractions - operate their own private water supplies.

The Australian drinking water guidelines offer guidance on safe drinking water ${ }^{1}$ and include a risk-based 'Framework for management of drinking water quality'. The framework moves away from reliance on endpoint testing, and encourages early identification and control of problems, thereby reducing the likelihood of contamination. 


\section{NSW Aboriginal Communities Water and Sewerage Program}

The NSW Aboriginal Communities Water and Sewerage Program provided an early opportunity to implement the Australian drinking water guidelines framework. Aboriginal people are disadvantaged in health outcomes², and the program, a joint initiative of the NSW Aboriginal Land Council and the NSW Government, aims to improve health and wellbeing by providing services equivalent to the standard expected in the wider community.

Before the program began in 2008, local Aboriginal land councils were responsible for water and sewerage infrastructure on their land. Most had small populations, and lacked the financial and technical capacity to sustain services. There was no systematic process for operation and maintenance of the infrastructure, and, in some communities, services did not meet general community standards. The program has committed more than $\$ 200$ million for 25 years for routine operation, maintenance, monitoring, repairs and replacement of infrastructure, and is providing services to more than 6000 people in 61 communities. Experienced service providers (generally local councils) are contracted to support the communities.

A risk-based water and sewerage management plan has been implemented for each community. The management plans have improved understanding and control of risks, resulting in safer, more reliable drinking water. Service providers now regularly monitor and report on drinking water quality, including chlorine residuals. In some communities, this has highlighted the need to optimise and improve water quality and disinfection. In addition, emergency works and new capital works have been implemented in dozens of communities. Engagement with communities is crucial, so local public health units have regular contact with communities, and participate with Department of Primary Industries (DPI) Water in 4-monthly inspections and reviews.

\section{NSW Drinking Water Monitoring Program}

For more than a century, NSW Health has provided drinking water testing for utilities. The current NSW Drinking Water Monitoring Program, provided by NSW Health, has been operating since 2001. The program offers free testing, guidance on sampling, and protocols for when contamination is detected. It has provided a mechanism for NSW Health to exercise public health oversight of regional utilities.

Routine tests include microbial indicators and physical/inorganic chemical characteristics. Monitoring results are stored in the internet-based NSW Drinking Water Database, which records results for more than 20000 samples per year. Utilities, NSW Health and government agencies can gain secure access to the database.

Before the current monitoring program began, 10\% of microbial samples were reported as noncompliant, and $27 \%$ of water supplies failed to submit samples. ${ }^{3}$ Since the monitoring program started, microbial compliance (Figure 1) and sampling adequacy (Figure 2) have improved significantly. This is probably the result of

Figure 1. Trend in microbial compliance in regional NSW by financial year (2001-15), using samples tested for Escherichia coli ( $p$ value $<0.001$ for trend test [Cochran-Armitage test])

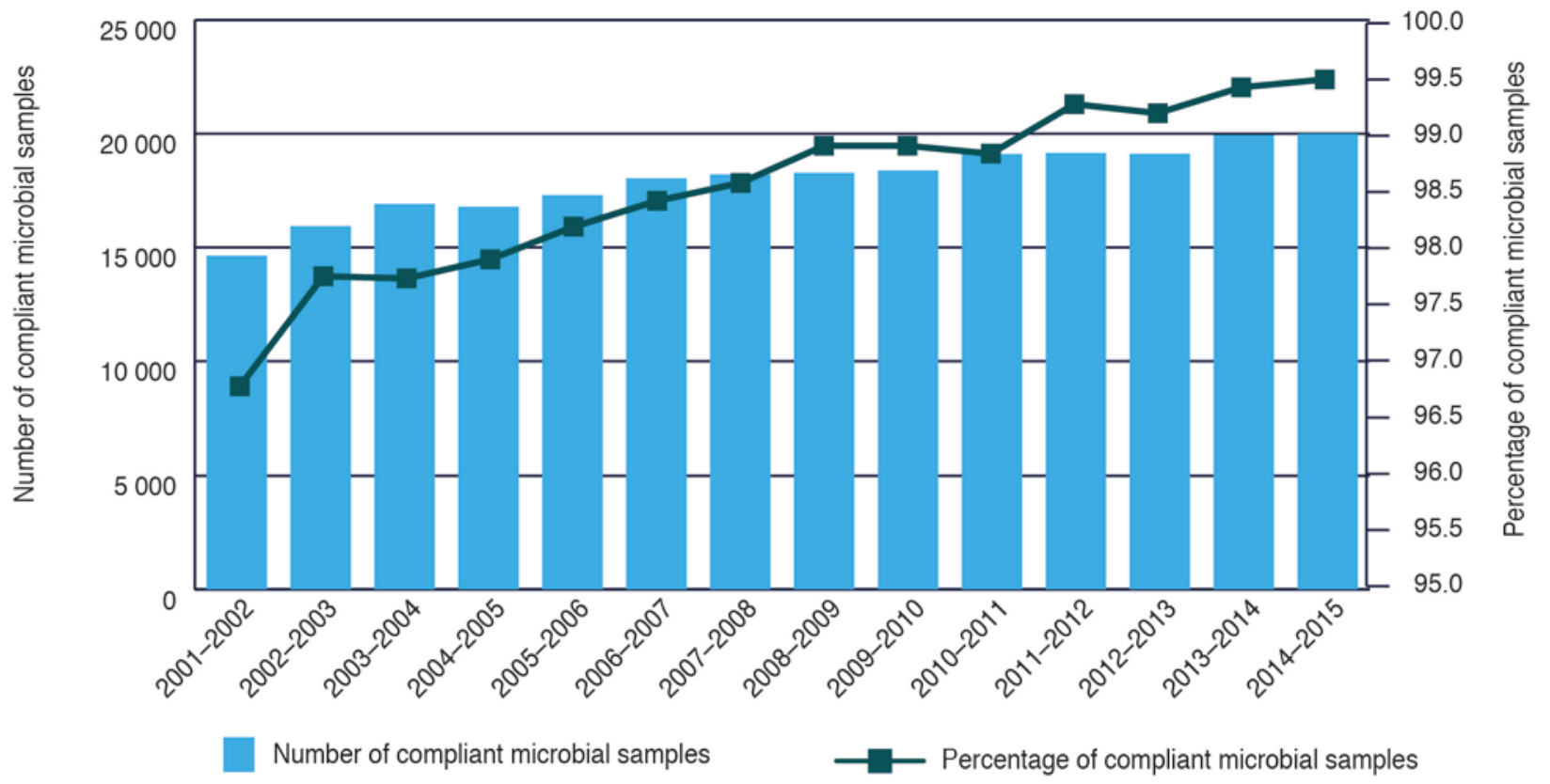

Source: NSW Drinking Water Database 
Figure 2. Trend in microbial sampling adequacy in regional NSW by financial year (2001-15), using samples tested for either Escherichia coli or thermotolerant coliforms ( $p$ value $<0.001$ for trend test [Cochran-Armitage test])

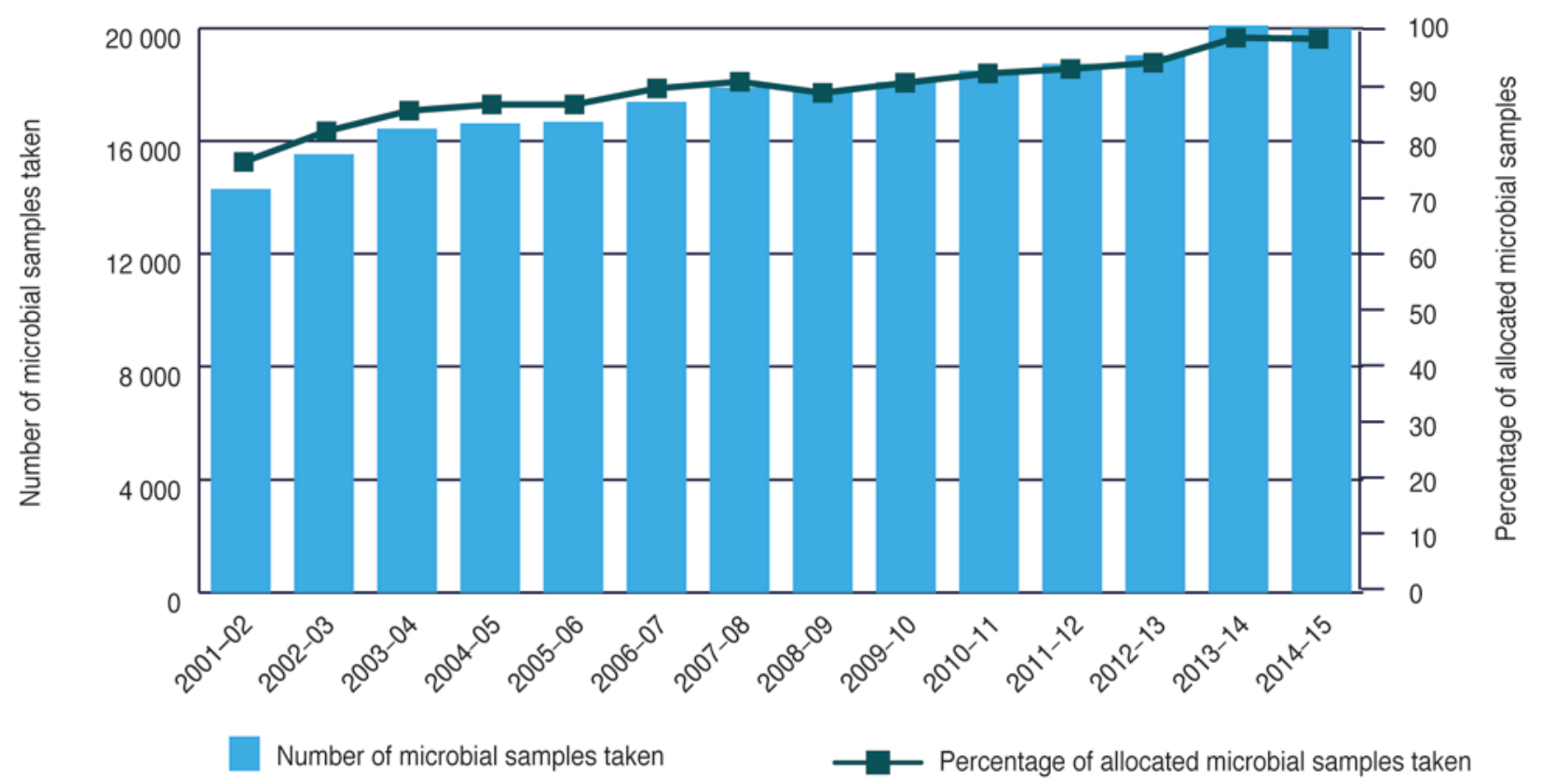

Source: NSW Drinking Water Database

many factors, including regular follow-up from public health units, improved reporting, improved sampling frequency, early detection and correction of problems, and a greater focus on treatment (including disinfection) and maintenance. ${ }^{4}$ Public health units work with utilities to investigate any noncompliant samples and assess the risk to the community.

Although the monitoring program promoted improved management, some problems remained: some small water supplies were below target for sampling frequency and water quality. A review of 107000 samples collected from 2001 to 2007 found that systems with inadequate disinfection or serving small populations were more vulnerable to contamination. ${ }^{5}$ Almost $40 \%$ of systems did not meet the target (i.e. no more than $2 \%$ of samples positive) for the faecal indicator Escherichia coli.

Detection of $E$. coli was significantly more common in the earlier years reviewed.

Similarly, a review of 214000 chemical and physical test results found that systems serving smaller populations or with higher turbidity had poorer healthrelated chemical compliance. ${ }^{6}$ Over the review period, $20 \%$ of systems did not comply with health guideline values. The most frequent noncompliant characteristics were levels of lead, antimony, nickel and manganese. These reviews helped influence a change in legislation to support safer drinking water.

\section{NSW Public Health Act 2010 - drinking water management systems}

The NSW Public Health Act 2010 requires all drinking water suppliers (including private suppliers and water carters) to implement a quality assurance program that addresses the 'Framework for management of drinking water quality'. ${ }^{7}$ NSW Health refers to the quality assurance program for a water utility as a 'drinking water management system' to emphasise the importance of implementing a system rather than simply preparing a plan. ${ }^{8}$ A drinking water management system consists of documents, procedures and other supporting information for the safe supply of drinking water. At the heart of a management system is monitoring of critical control points (CCPs) - those components of supply systems that control health risks (e.g. postfilter turbidity, chlorine).

Because the new legislative requirement to implement a quality assurance program was a major change, especially for some smaller utilities, NSW Health gave utilities a long transition period (until 1 September 2014) to establish their systems. NSW Health worked closely with utilities and industry to promote awareness of the requirements and share information, and offered all regional utilities support for development of management systems; 74 of 95 utilities requested support. NSW Health contracted skilled water quality and engineering specialists to help. Over the past 4 years, utilities and 
NSW Health (public health units and the Water Unit) have participated in almost 100 risk assessment workshops.

Additional support is being given to utilities to help them implement management systems and identify barriers to implementation, and provide recommendations and solutions (including for improved operational monitoring and optimisation of water treatment).

\section{Benefits of drinking water management systems}

To gain a systematic understanding of benefits and challenges, public health units are now reviewing the first annual reports of implementation of management systems, which are required from all utilities. To date, 32 utilities have identified a range of benefits. These include having one central source of information to manage all components of a water supply, increased staff awareness of critical processes, and a greater ability to identify improvements (through close inspection of infrastructure and enhanced monitoring). For example, a western NSW utility has automated the removal of sediment from the clarifier at its water treatment plant. The town now benefits from safer drinking water with lower turbidity, in line with the Australian drinking water guidelines. Also, a southern NSW utility recently issued a 'boil water alert' when heavy rains caused a deterioration in raw water turbidity. Close monitoring of turbidity as a CCP allowed a prompt response, protecting the community from potential illness.

\section{Next steps}

The development of management systems has highlighted that further improvements are required. NSW Health is working with DPI Water and utilities to support the ongoing implementation, review and audit of management systems. Water utilities and DPI Water are integrating Aboriginal community water management plans into utility drinking water management systems. NSW Health is continuing engagement with specialist contractors and utilities to review management systems, CCP performance, risk assessment findings, and actions and improvements. NSW Health is also developing a model to identify systems at highest risk from Cryptosporidium to ensure that treatment is optimised.

Regular review of CCP performance is essential to maintain effective operation of treatment processes and ensure safe drinking water. NSW Health has developed templates for short-term evaluation of CCP performance and annual review of management systems. External audits will also be undertaken in the coming years.

\section{Private water suppliers and water carters}

Since 2007, NSW Health has recommended that private water suppliers implement a risk-based quality assurance program, and this is now required by the Public Health
Act 2010. NSW Health has worked closely with local councils, government agencies and industry associations to promote awareness of requirements for private water suppliers and water carters. It has also published updated NSW private water supply guidelines ${ }^{9}, N S W$ guidelines for water carters ${ }^{10}$ and water treatment fact sheets. Quality assurance program templates have been developed for different types of private water supplies including bore water, river water and rainwater systems - and for water carters.

\section{Conclusion}

The Public Health Act 2010 has increased awareness of drinking water risk management among water suppliers, and offers a systematic process for risks to be identified and controlled. This has benefited water utilities, smaller private suppliers, and remote and Aboriginal communities.

NSW Health recognised the importance of supporting regional utilities, especially those with limited engineering expertise and financial capacity. Because of the continuing need to identify and control potential risks in catchments, treatment plants and distribution systems, NSW Health is continuing to give this support where needed to help ensure that all communities can enjoy safe drinking water.

Ultimately, it is the responsibility of water suppliers to provide safe drinking water to consumers. Quality assurance programs offer a structured, risk-based approach to ensure safe drinking water. Continued engagement and support will be necessary to ensure implementation of such programs by all utilities, private suppliers and water carters.

\section{Acknowledgements}

The authors acknowledge the support of NSW public health units, NSW DPI Water, Zenah Bradford-Hartke, Ebony Heslop, Tran Huynh, Edward Jegasothy, Michelle Phoenix and Jeff Standen.

\section{Competing interests}

None declared

\section{Author contributions}

Each author contributed to the writing and the work reported (i.e. development of the drinking water quality assurance processes). 


\section{References}

1. National Health and Medical Research Council, National Resource Management Ministerial Council. Australian drinking water guidelines 6. Canberra: Commonwealth of Australia; 2011 [cited 2015 Oct 23]. Available from: www.nhmrc.gov.au/_files_nhmrc/file/publications/nhmrc_ adwg_6_february_2016.pdf

2. Commonwealth of Australia. Closing the gap: Prime Minister's report 2015. Canberra: Commonwealth of Australia; 2015 [cited 2016 Jan 5]. Available from: www. dpmc.gov.au/sites/default/files/publications/Closing_the_ Gap_2015_Report_0.pdf

3. Cowie C, Corbett S. Surveillance of rural drinking water quality in NSW. N S W Public Health Bull. 1994;5(4):35-9.

4. Byleveld PM, Cretikos MA, Leask SD, Durrheim DN. Ensuring safe drinking water in regional NSW: the role of regulation. N S W Public Health Bull. 2008;19(11-12): 203-7.

5. Cretikos M, Byleveld $P$, Durrheim DN, Porigneaux $P$, Merritt T, Leask S. Supply system factors associated with microbiological drinking water safety in regional New South Wales, Australia, 2001-2007. J Water Health. 2010;8(2):257-68.

6. Li L, Byleveld P, Leask A, Smith W. Assessment of chemical quality of drinking water in regional New South Wales, Australia. Cairns: Proceedings of the 18th World IMACS congress and MODSIM09 international congress on modeling and simulation; 2009 [cited 2016 Feb 10]. Available from: www.mssanz.org.au/modsim09/J3/li_I.pdf
7. New South Wales Government. Public Health Act 2010. Sydney: NSW Government; 2010 [cited 2015 Oct 23]. Available from: www.legislation.nsw.gov.au/maintop/view/ inforce/act $+127+2010+\mathrm{cd}+0+\mathrm{N}$

8. NSW Health, NSW Department of Primary Industries - Office of Water. NSW guidelines for drinking water management systems. Sydney: NSW Government; 2013 [cited 2015 Oct 23]. Available from: www.health.nsw.gov. au/environment/water/Publications/NSW-Guidelines-forDrinking-Water-Management-Systems.pdf

9. NSW Health. NSW private water supply guidelines. Sydney: NSW Health; 2014 [cited 2015 Oct 23]. Available from: www.health.nsw.gov.au/environment/water/ Publications/private-water-supply-guidelines.pdf

10. NSW Health, NSW Food Authority. NSW guidelines for water carters. Sydney: NSW Government; 2012 [cited 2015 Oct 23]. Available from: www.health.nsw.gov.au/ environment/Publications/nsw-guidelines-for-watercarters.pdf

\section{Copyright: (c) (i) (2)}

(C) 2016 Byleveld et al. This article is licensed under the Creative Commons Attribution-NonCommercial-ShareAlike 4.0 International Licence, which allows others to redistribute, adapt and share this work non-commercially provided they attribute the work and any adapted version of it is distributed under the same Creative Commons licence terms. See: www.creativecommons.org/licenses/by-nc-sa/4.0/ 